\title{
Superior vena cava syndrome and lung cancer: survival and prognostic factors
}

\author{
Abstract \\ Introduction: The superior vena cava syndrome (SVCS) is a set of signs related to the \\ obstruction of the upper cava current caused by a compression, an invasion or a thrombosis \\ of the superior vena cava. Its etiologies are numerous but dominated by neoplastic causes \\ mainly of bronchopulmonary origin.
}

Aim of the work: The aim of this study is to evaluate survival and to identify the prognostic factors of superior vena cava syndrome in patients with lung cancer. We also propose to draw up the clinical profile as well as the therapeutic management in SVCS of malignant origin.

Materials and methods: A total of 108 patients with SVCS complicating primary bronchia cancer were hospitalized in the Pneumology Department at Fattouma Bourguiba University Hospital during a period of 25 years.

Results: The results showed the existence of a clear male predominance $(98.1 \%)$ and an average age of 60.2 years. Smoking was found in $68.5 \%$ of cases .The superior vena cava syndrome revealed a neoplasm in $55 \%$ of cases and it was metachronous in $30.5 \%$ of cases. Median survival was 7 months. In univariate study, survival was reduced in patients having general health impairment with Performans Status (PS) score $\geq 2$, signs of severity of SVCS, altered respiratory function, chronic respiratory failure, histological type of non small cell lung carcinoma and exclusive symptomatic treatment for bronchopulmonary cancer. Multivariate analysis revealed that gender, smoking, PS score and signs of severity were independent prognostic factors.

Conclusion: The management of the SVCS is multidisciplinary. It requires medical treatment whose effectiveness is still uncertain and radiotherapy which is considered the gold standard of treatment for SVCS.

Keywords: Superior vena cava syndrome, broncho-pulmonary cancer, radiotherapy, survival, prognostic factors
Volume 6 Issue 4 - 2019

\author{
Nesrine Fahem, Asma Migaou, Ahmed \\ Ben Saad, Sameh Jobeur, Saoussen cheikh \\ Mhammed, Naceur Rouatbi \\ Department of Pneumology, Fattouma Bourguiba University \\ Hospital,Tunisia
}
Correspondence: Asma Migaou, Department of Pneumology, Fattouma Bourguiba University Hospital,Tunisia, Emailmigaou.asma@gmail.com

Received: September 24, 2019 | Published: November 15, 2019
Abbreviations: SVCS, Superior vena cava syndrome; SVC, Superior vena cava; BPC, Bronchopulmonary carcinoma; NSCLC, Non small cell lung cancer; SCLC, Small cell lung cancer; CT scan, Computed Tomography N: number; WHO, World Health Organization; PS, Performans Status; FEV1, Forced expiratory volume in one second; $\mathrm{PaO} 2$, Partial Pressure of Oxygen in arterial blood; BMI, Body mass index; HR, Hazard ratio; CI, Confidence interval

\section{Introduction}

Superior vena cava syndrome (SVCS) is the clinical expression of superior vena cava (SVC) obstruction by extrinsic compression, vein invasion by a tumoral process, or thrombosis. The clinical manifestations are related to the increase of the venous pressure upstream of the obstruction and they depend on how fast it has been installed. ${ }^{1}$ Many etiologies have been described and their importance has changed over the years. While in the first half of the twentieth century, infectious diseases were the main causes of the superior vena cava syndrome, mediastinal and malignant lung tumors are currently the most common etiologies. This syndrome occurs in 3 to $4 \%$ of cancer patients and in $85 \%$ of cases it is secondary to bronchopulmonary carcinoma (BPC). These cancers occupy the first place among malignant tumors in men and the third one of women. Non-small cell lung cancer (NSCLC) accounts for more than $80 \%$ of bronchial cancers. ${ }^{2}$ Small cell lung cancer (SCLC) is a risk factor of SVCS because of its mediastinal predilection and speed of progression.

The clinical manifestation may be discreet or, on the contrary, life-threatening. ${ }^{3}$ The prognosis of SVCS depends essentially on the underlying cause. In BPC, the 5-year survival rate is 2 to $5 \%$. The aim of this study is to evaluate the survival of patients with SVCS secondary to lung cancer and to identify prognostic factors.

\section{Methods}

\section{Type of the study:}

In the current retrospective study, we enrolled the records of patients followed for SVCS due to primary bronchopulmonary cancer in the Department of Pneumology, Fattouma Bourguiba University Hospital in Monastir from 1990 to 2015.

\section{Study population:}

\section{Inclusion criteria:}

We included in this study: The presence of clinical and/or radiological SVCS in patients with histologically confirmed primary BPC, the age $\geq 18$ years and SVCS confirmed by chest Computed Tomography (CT-scan). 


\section{Non-inclusion criteria:}

We excluded all cases whose diagnosis has not been confirmed histologically, SVCS linked to secondary lung cancer, age $<18$ years and SVCS linked to other tumors (lymphoma) or of non tumoral origins (infections).

\section{Survival:}

It is the time between the date of diagnosis of SVCS of neoplastic origin and the date of death or the date of the latest news of the patients. The collection of patient survival data was based on medical record data for patients who died in hospital and telephone contact with the family of home-deceased patients.

\section{Statistical analysis and study of prognostic factors:}

The data collected was coded and analyzed using the SPSS version 21 software. The quantitative variables were expressed as means \pm standard deviations. The qualitative variables were expressed in percentages. The survival analysis was performed by the KaplanMeier method. The comparison of the survival according to the different prognostic variables was made by the Log-Rank test in a univariate analysis. The multivariate analysis was performed by the Cox model to identify independent factors. The model included all variables with a $\mathrm{p}<0.2$ value in univariate analysis. The results were evaluated with a $95 \%$ confidence interval and a $\mathrm{p}$ value $<0.05$ was considered significant.

\section{Results}

a) Demographic characteristics of the studied population:

A total of 108 patients were included in our study. The general characteristics of the patients are detailed in (Table 1).

Table I Demographic characteristics of the studied population

\begin{tabular}{ll}
\hline & Studied population : N= $\mathbf{0 8}$ \\
\hline $\begin{array}{l}\text { Age (year) M } \pm D S \\
\text { Gender }\end{array}$ & $60.2 \pm 1 \mathrm{I} .3$ \\
Male & $106(98 \%)$ \\
Female & $2(2 \%)$ \\
Smoking & $68.50 \%$ \\
Year-Pack (YP) & 55.1 YP \pm 27.2 YP \\
Medical History & \\
COPD & $25(23.5 \%)$ \\
Diabetes & $14(12.9 \%)$ \\
Hypertension & $12(11.1 \%)$ \\
\hline
\end{tabular}

\section{b) Clinical manifestations:}

The clinical manifestations of the primary BPC as well as the clinical signs suggestive of SVCS at the time of the diagnosis are displayed in (Table 2). SVCS revealed the tumor in 60 cases $(55 \%)$ and

\section{c) Characteristics of the primary tumor:}

A histopathological confirmation was carried out in all patients. SCLC was at an extensive stage in $70.5 \%$ of cases. NSCLC was diagnosed at an advanced stage in 35 patients (54.7\% of cases). The histological types along with the stage of the carcinoma are shown in (Table 3).

\section{d) Treatment:}

The management of the patients involved two components: the symptomatic treatment of the superior vena cava syndrome and the management of BPC. Symptomatic treatment of SVCS consisted on Oxygen therapy in 15 patients $(13.4 \%)$, corticosteroids in 93 patients $(68.1 \%)$, radiotherapy for decompression in 42 patients $(38.8 \%)$, anticoagulation in 30 patients $(27.7 \%)$ and diuretics in only 1 patient. Management of bronchopulmonary cancer included symptomatic measures in 106 patients (98.1\%), chemotherapy in 85 patients (78.7\%) and curative radiation in 27 patients $(25 \%)$.

Table 2 Clinical manifestations

\begin{tabular}{ll}
\hline Clinical manifestations of BPC & Number (percentage ) \\
\hline Chest pain & $62(57.4 \%)$ \\
Cough & $56(51.8 \%)$ \\
Dyspnea & $47(43.5 \%)$ \\
Hemoptysis & $30(28.7 \%)$ \\
Clinical signs of SVCS & Number (percentage ) \\
Facial edema & $63(67.7 \%)$ \\
Collateral vein circulation & $57(61.2 \%)$ \\
Increased neck volume & $38(40.8 \%)$ \\
Distention of the veins in the neck & $35(37.6 \%)$ \\
Cyanosis & $5(5.3 \%)$ \\
Upper limbs edema & $19(20.4 \%)$ \\
\hline
\end{tabular}

Table 3 Characteristics of the primary tumor

\begin{tabular}{ll}
\hline Anatomopathology & \\
\hline SCLC & $43(40.1 \%)$ \\
Squamous cell carcinoma & $33(29.9 \%)$ \\
Adenocarcinoma & $29(26.1 \%)$ \\
Large cell carcinoma & $3(2.9 \%)$ \\
Stages & \\
SCLC & \\
Limited stage & $13(29.5 \%)$ \\
Extensive stage & $31(70.5 \%)$ \\
NSCLC & \\
IIIA & $10(15.6 \%)$ \\
IIIB & $19(29.7 \%)$ \\
IV & $35(54.7 \%)$ \\
\hline
\end{tabular}

SCLC: Small cell lung carcinoma

NSCLC: Non small cell lung carcinoma

\section{e) Survival and prognostic factors:}

\section{A. Overall survival:}

By 2015,89 patients $(82.4 \%)$ had died, 9 patients had survived $(8.3 \%)$ and 10 patients had defaulted from follow-up. The median survival of our patients was 7 months. Survival at 1 and 2 years was $22 \%$ and $6 \%$, respectively.

\section{B. Prognostic factors:}

\section{a. Univariate study:}

In univariate study, poor prognostic factors are bad general health, documented by the World Health Organisation (WHO) performans status (PS) score $\geq 2$, signs of severity of SVCS, ventilatory deficit with 
forced expiratory volume in one second (FEV1) $<70 \%$ of baseline in spirometry , chronic respiratory failure confirmed by Partial Pressure of Oxygen in arterial blood $(\mathrm{PaO} 2)<70 \mathrm{mmHg}$, histological type of NSCLC and exclusive symptomatic treatment for NSCLC and SCLC (Table 4).

\section{b.Multivariate study:}

Predictors of superior vena cava syndrome mortality during BPC were: Male gender, smoking, $\mathrm{PS} \geq 2$, two or more metastases and the presence of SVCS severity signs (Table 5).

Table 4 Survival and prognostic factors in univariate study

\begin{tabular}{|c|c|c|c|}
\hline & Number of cases & Median survival in months & p value \\
\hline \multicolumn{4}{|l|}{ Age } \\
\hline$\leq 60$ years & 51 & $6 \pm 1.07$ & 0.22 \\
\hline$>60$ years & 57 & $7 \pm 0.81$ & \\
\hline Gender & & & 0.14 \\
\hline Men & 107 & $7 \pm 0.60$ & \\
\hline Women & 1 & $3.5 \pm 0.60$ & \\
\hline \multicolumn{4}{|l|}{ Smoking status } \\
\hline Non-smokers or ex-smoker & 34 & $8 \pm 1.57$ & \\
\hline CurrentSmokers & & & 0.13 \\
\hline \multicolumn{4}{|l|}{ PS Score } \\
\hline$<2$ & 80 & $8 \pm 0.60$ & $<10^{-3 *}$ \\
\hline$\geq 2$ & 28 & $3.5 \pm 0.79$ & \\
\hline \multicolumn{4}{|l|}{ Severity Signs of SVCS } \\
\hline No & 100 & $7 \pm 0.57$ & $0.02 *$ \\
\hline Yes & 8 & $3 \pm 0.91$ & \\
\hline \multicolumn{4}{|l|}{ BMI } \\
\hline$<18,5$ & 10 & $6 \pm 3.55$ & \\
\hline $18,5-24,99$ & 44 & $7 \pm 0.68$ & 0.07 \\
\hline$\geq 25$ & 15 & $10 \pm 5.87$ & \\
\hline \multicolumn{4}{|l|}{ FEVI } \\
\hline$<70 \%$ & 48 & $6 \pm 0.83$ & $0.04 *$ \\
\hline$\geq 70 \%$ & 23 & $9 \pm 1$ & \\
\hline \multicolumn{4}{|l|}{$\mathrm{PaO} 2$} \\
\hline$<70 \mathrm{mmHg}$ & 17 & $4 \pm 0.5$ & \\
\hline$\geq 70 \mathrm{mmHg}$ & 62 & $8 \pm 0.74$ & $0.01 *$ \\
\hline \multicolumn{4}{|l|}{ Histology } \\
\hline NSCLC & 64 & $5 \pm 0.60$ & $0.002^{*}$ \\
\hline SCLC & 44 & $8.5 \pm 0.94$ & \\
\hline \multicolumn{4}{|l|}{ TNM stages } \\
\hline \multicolumn{4}{|l|}{ NSCLC } \\
\hline IIIA & 10 & $6 \pm 1.4 \mid$ & 0.13 \\
\hline IIIB & 19 & $9 \pm 1.8$ & \\
\hline IV & 35 & $5 \pm 0.54$ & \\
\hline \multicolumn{4}{|l|}{ SCLC } \\
\hline Limited & 13 & $13 \pm 2.37$ & 0.11 \\
\hline Extensive & 31 & $7 \pm 1.04$ & \\
\hline \multicolumn{4}{|l|}{ Treatment of NSCLC } \\
\hline Symptomatic treatment & 18 & $4 \pm 0.04$ & \\
\hline Chemotherapy or Radiotherapy & 46 & $9.6 \pm 0.8$ & $<10^{-3 *}$ \\
\hline \multicolumn{4}{|l|}{ Treatment of SCLC } \\
\hline \multicolumn{4}{|l|}{ Symptomatic treatment } \\
\hline Radio-chemotherapy & 5 & 3 & $<10^{-3 *}$ \\
\hline \multirow[t]{2}{*}{ Chemotherapy } & 13 & $29 \pm 11$ & \\
\hline & 29 & $8.5 \pm 1.28$ & \\
\hline
\end{tabular}

* Significant BMI: Body mass index 
Table 5 Independent factors of mortality in SVCS

\begin{tabular}{llll}
\hline & HR & IC 95\% & P value \\
\hline Male gender & 13.78 & I.7-III.9 & $0.01 *$ \\
Smoking & 1.78 & $1.1-2.9$ & $0.01 *$ \\
PS $\geq 2$ & 5.28 & $2.9-9.5$ & $<10^{-3 *}$ \\
SVCS Severity signs & 2.59 & $1.08-6.17$ & $0.03^{*}$
\end{tabular}

* Significant HR: Hazard ratio

$\mathrm{Cl}$ : Confidence interval

\section{Discussion}

The SVCS is the clinical expression of superior vena cava (SVC) obstruction by extrinsic compression or thrombosis most commonly due to an invasive process. Bronchopulmonary cancer accounts for $80-85 \%$ of the most common etiology of SVCS in adults. ${ }^{4}$ The current study investigated the prognostic factors of SVCS in patients with bronchopulmonary cancer. Despite the therapeutic progress and the fast management of the SVCS of broncho-pulmonary tumor origin, this entity remains of poor prognosis. In our study, the median survival was 7 months. Poor prognosis factors were male gender, smoking, general impairment and the presence of severity signs of SVCS. The median survival varies depending on the authors from 6 to 9 months, ${ }^{3-7}$ which is consistent with our study (7 months). Survival at 2 years in our series was $6 \%$.

It is reported in the literature that life expectancy in patients with tumour SVCS is 6 months, but this estimation varies widely depending on the underlying neoplastic conditions. ${ }^{8,9}$ According to some authors, the SVCS itself is not a factor of poor prognosis since overall survival does not differ for BPC of the same histological type and same stage according to the existence or not of SVCS..$^{5,6,8}$ Most studies have found that age is an important factor influencing the prognosis of SVCS of pulmonary neoplastic origin with a survival that deteriorates with age. ${ }^{3,10}$ In fact, Chan RCL proved in his study about 104 patients with tumour SVCS that the age under 50 years was associated with better survival in univariate study $\left(\mathrm{p}<10^{-3}\right) .{ }^{6}$ However, in our series, age 60 or younger is correlated with a shorter median survival (6 months versus 7 months), but the difference was statistically insignificant. This could be explained by the predominance of the 61-70 age groups.

Smoking is the main risk factor for bronchopulmonary cancer. The absence of smoking in our series is correlated with better survival but the difference was statistically insignificant. Several studies have shown that the survival of non-smoking patients with SVCS of pulmonary tumors was better than that of smokers. Indeed, Piers NF and al found better overall survival in non-smokers with a significant difference $(p=0.038){ }^{5}$ The general condition assessment of the patient is an essential step in the management of bronchopulmonary cancer with SVCS. The therapeutic decision depends on the general condition. In our series, patients with a PS of two or more had lower survival than patients with good general health $\left(\mathrm{p}<10^{-3}\right)$. Several studies have shown that good general health is associated with better survival. ${ }^{3,5,7,10-12}$ Indeed, Piers NF and al found that a good PS score of 0 or 1 was positively correlated with global survival $(\mathrm{p}=0.03){ }^{5}$

According to the literature review, the degree of bronchial obstruction negatively influences the survival of patients with BPC associated with chronic obstructive pulmonary disease. This association is frequent since both pathologies carry the same risk factor (tobacco). ${ }^{13,14}$ In our patients, FEV $1<70 \%$ was associated with lower survival with statistically significant difference $(\mathrm{p}=0.04)$. In addition, median survival was lower $(4 \pm 0.5$ months versus $8 \pm 0.7$ months) in chronic respiratory failure $(p=0.01)$. The review of the literature regarding survival as a function of the histological type has shown variable results. Several studies have shown that the survival of patients with NSCLC is better compared with those with SCLC. ${ }^{8,9}$ On the other hand, Wilson LD reported in his study that the prognosis of SVCS with neoplastic origin depends on histological type of the tumor and its response to treatment. He concluded that SCLC was correlated with better survival. ${ }^{8}$

In our series, patients with SCLC had a longer median survival than those with NSCLC (8.5 months versus 5 months) with a statistically significant difference. The presence of metastasis is an important prognostic factor for SVCS of neoplastic origin., ${ }^{3,5,9-11}$ Survival in our patients was better for localized or locally advanced stages but the difference was statistically insignificant. Concerning cancer treatment, a better survival was noted under chemotherapy $(8$ months) with a statistically significant difference in case of NSCLC $\left(\mathrm{p}<10^{-3}\right)$ and in case of SCLC $\left(\mathrm{p}<10^{-3}\right)$ in our series. According to Wilson LD ${ }^{8}$ a complete regression of symptoms of SVC obstruction is visible under routine chemotherapy in $80 \%$ of patients with SCLC and $40 \%$ of those with NSCLC. However, Rowell NP, in a systemic review of 2 randomized studies and 44 observational studies, concluded that in patients with bronchopulmonary cancer, there was no significant difference in SVCS remission rate or in overall survival depending on the treatment prescribed: chemotherapy alone or chemo-radiotherapy. ${ }^{15}$

The main independent prognostic factors vary between studies. The study of Piers NF allowed to identify some independent factors of good prognosis: a good general state ( $\mathrm{PS}=0$ or 1 ), the absence of metastases and the absence of smoking. ${ }^{5}$ Indeed, the PS is an important prognostic factor found in multi-variate analysis in several studies. ${ }^{3,5}$ Smoking was a risk factor for mortality., 5 Early tumor stage and absence of metastasis were positively correlated with a better overall survival. ${ }^{5}$ In our series, the predictive factors for SVCS mortality in bronchopulmonary cancer were: male gender, smoking, general impairment with PS $\geq 2$, two or more metastases, and SVCS signs of severity.

\section{Conclusion}

The etiologies of SVCS are numerous dominated by neoplastic causes mainly of bronchopulmonary cancer. Despite therapeutic progress of the SVCS of broncho-pulmonary tumor origin, this entity remains of guarded prognosis. The independent factors of poor prognosis were male gender, smoking, general impairment and SVCS signs of severity. Early detection and adequate treatment of SVCS is the key to a better survival among patients with bronchopulmonary cancer.

\section{Funding}

None.

\section{Acknowledgments}

None. 


\section{Conflict of interest}

Authors declare that there is no conflict of interest.

\section{References}

1. Limal N, Wechsler B. Superior cellar syndromes. Blood Thrombosis Vessels. 2006;18(1):17-22.

2. Blel S. Broncho-pulmonary cancer non-petite cells: survie et facteurs pronostiques. 2015.

3. Bellefqih S, Khalil J, Mezouri I, et al. Syndrome cave supérieurd'originemaligne. Revue de Pneumologie Clinique. 2014;70:343-352.

4. Rice TW, Rodriguez RM, Light RW. The superior vena cava syndrome: clinical characteristics and evolving etiology. Medecine (Baltimore). 2006;85(1):37-42.

5. Pires NF, Morais A, Queiroga H.Superior vena cava syndrome as tumour presentation. Rev Port Pneumol. 2010;16 (1):73-88.

6. Chan RCL, Chan YC, Cheng SWK. Mid-and long term follow up experience in patients with malignant superior vena cava obstruction. Interact Cardiovasc Thorac Surg. 2013;16;455-458.

7. Mose S, Stabik C, Eberlein K, et al. Retrospective analysis of the superior vena cava syndrome in irradiated cancer patients. Anticancer Res. 2006;26(6):4933-4936
8. Wilson LD, Detterbeck FC, Yahalom J. Superior vena cava syndrome with malignant causes. N Engl J Med. 2007;356:1862-1869.

9. Wang J, Liang J, Wang W, et al. Malignant thrombosis of the superior vena cava caused by non-small-cell lung cancer treated with radiation and erlotinib: a case with complete and prolonged response over 3 years. Onco Targets Ther. 2013;6:749-53.

10. Schraufnagel DE, Hill R, Leech JA, et al. Superior vena cava obstruction: is it a medical emergency? Am J Med. 1981;70(6):1169-1174.

11. Yellin A, Rosen A, Reichert N. Superior vena syndrome: the myth, the facts. A Rev Respir Dis. 1990; 141(5):1114-1118.

12. Jindal SK, Behera D. Clinical spectrum of primary lung cancer- Review of Chandigarh experience of 10 years. Lung india 1990;8(2):94-8.

13. Putila J, GuoNL. Combining COPD with clinical, pathological and demographic information refines prognosis and treatment response prediction of non-small cell lung cancer. PLos One. 2014;9(6):e100994.

14. Kim H, Lussier YA, Noh OK, et al. Prognostic implication of pulmonary function at the beginning of postoperative radiotherapy in non-small cell lung cancer. Radiother Oncol. 2014;113(3):374-378.

15. Rowell NP, Gleeson FV. Steroids, radiotherapy, chemotherapy and stents for superior vena cava obstruction in carcinoma of the bronchus: a systematic review. ClinOncol (R CollRadiol). 2002;14(5):338-351. 